\title{
Sub-Ångstrom Metrology of Resolution in Aberration-Corrected Transmission Electron Microscopes using the A-OK Standard Test Specimens
}

\author{
Lawrence F. Allard* and Michael A. O'Keefe** \\ *Metals and Ceramics Division, ORNL, Oak Ridge, TN 37831-6064, USA \\ **Materials Sciences Division, LBNL 2-200, 1 Cyclotron Road, Berkeley, CA 94720, USA
}

DISCLAIMER

This document was prepared as an account of work sponsored by the United States Government. While this document is believed to contain correct information, neither the United States Government nor any agency thereof, nor The Regents of the University of California, nor any of their employees, makes any warranty, express or implied, or assumes any legal responsibility for the accuracy, completeness, or usefulness of any information, apparatus, product, or process disclosed, or represents that its use would not infringe privately owned rights. Reference herein to any specific commercial product, process, or service by its trade name, trademark, manufacturer, or otherwise, does not necessarily constitute or imply its endorsement, recommendation, or favoring by the United States Government or any agency thereof, or The Regents of the University of California. The views and opinions of authors expressed herein do not necessarily state or reflect those of the United States Government or any agency thereof, or The Regents of the University of California.

Ernest Orlando Lawrence Berkeley National Laboratory is an equal opportunity employer.

Ernest Orlando Lawrence Berkeley National Laboratory - LBNL-55691 


\title{
Sub-Ångstrom Metrology of Resolution in Aberration-Corrected Transmission Electron Microscopes using the A-OK Standard Test Specimens
}

\author{
Lawrence F. Allard* and Michael A. O'Keefe** \\ * Metals and Ceramics Division, ORNL, Oak Ridge, TN 37831-6064, USA \\ **Materials Sciences Division, LBNL 2-200, 1 Cyclotron Road, Berkeley, CA 94720, USA
}

Two concurrent revolutions are driving the need for generally accepted resolution standards for subÅngstrom and near-sub- $\AA$ microscopy. Aberration correction has produced a paradigm shift in sub$\AA$ electron microscope technology (both TEM and STEM), and the current revolution in nanoscale science and technology requires instrumentation for observation and metrology (we must be able to measure, as well as see, what we build). Nano-devices operating at the level of a few atoms require accurate atomic-scale imaging for characterization. High-resolution aberration-corrected electron microscopes (both TEM and STEM) are able to provide these measurements to the sub- $\AA$ level.

In general, resolution is the ability to determine if an image feature represents two objects rather than one. Rayleigh's original resolution criterion, an accepted standard in optics, was derived as a means for judging when two sources of light (stars) were distinguishable from a single source [1]. In the field of microscopy, resolution is the ability to determine if detail in an image represents distinct (separated) objects. In high-resolution TEM, structural information from the specimen is encoded in the phase of the scattered electron waves. Interference of these scattered electron waves allows us to image the relative phases of the waves as peaks that map the atom positions and scattering power. Resolution of $|\mathbf{d}|$ is achieved when atoms separated by a (projected) distance $|\mathbf{d}|$ can be perceived as separate objects. Demonstration of resolution $|\mathbf{d}|$ requires the presence of the corresponding spatial frequency $1 /|\mathbf{d}|$ in the TEM image spectrum, but the mere presence of the $1 /|\mathbf{d}|$ frequency is not sufficient to demonstrate a corresponding resolution of $|\mathbf{d}|[2]$. In the STEM a probe size of $|\mathbf{d}|$ is a necessary, but not sufficient, requirement to achieve a resolution of $|\mathbf{d}|$. We propose that both TEM and STEM use the same (Rayleigh) standard of resolution - separation of atom peaks in the image.

Using specimens with diamond cubic and zincblende structures, oriented to provide pairs of atoms in "dumbbell" configurations, we have identified specimens with well-characterized atom separations over a 3:1 range of spacings straddling the canonical $1 \AA$ value. Fig. 1 (top) shows how spacings ranging from $1.6 \AA$ to $0.5 \AA$ are available from an "A-OK" set of test specimens carefully selected for their stability and well-characterized lattice parameters [3].

Two of the A-OK series in figure 1 have been used as test specimens [4] to characterize the sub- $\AA$ resolution of the LBNL One-Ångstrom Microscope (OÅM) [5]. The OÅM combines a modified CM300FEG/UT high-resolution TEM with FEI focal-series reconstruction software by Coene and Thust $[6,7]$ to achieve sub- $\AA$ resolution to $0.78 \AA$ [4]. OAM results presage those from the coming generation of hardware-corrected microscopes. OAM images of [110] diamond and [112] silicon, taken from the A-OK series show carbon atoms (Fig. 1 left) clearly separated by 0.89A [5], and (at the resolution limit of the OAM) silicon atoms (Fig. 1 right) separated by $0.78 \AA$. Sub- $\AA$ HR-STEMs have produced similar dumbbell images from [110] germanium-silicon [8] and [112] silicon [9].

To characterize nanomaterials, we must see all the atoms. Improving the resolution narrows the heavy atom peaks, allowing lighter atom peaks to emerge. The OAM has demonstrated that sub- $\AA$ resolution gives TEMs ability to image light atoms down to lithium, lightest of all metal atoms [10]. Improvements in resolution provide separation of atom columns in many more projection directions and produce improved three-dimensional characterization of the shapes and internal structures of nano-devices and catalyst nanoparticles [11]. TEMs and STEMs provide essential feedback in the nano-theory/construction/measurement loop (soon even 3-D imaging). Test specimens will be needed for calibration as TEM and STEM resolutions are extended to half- $\AA$ levels by next-generation aberration-corrected electron microscopes [12]. The A-OK test series will be able to fill this role by providing tests for resolutions down to $0.5 \AA$. Although many crystalline samples with discrete atom columns of known spacing could be used, the A-OK test series is particularly suitable as a resolution standard because all the members have structures that produce standardized dumbbells [13]. 


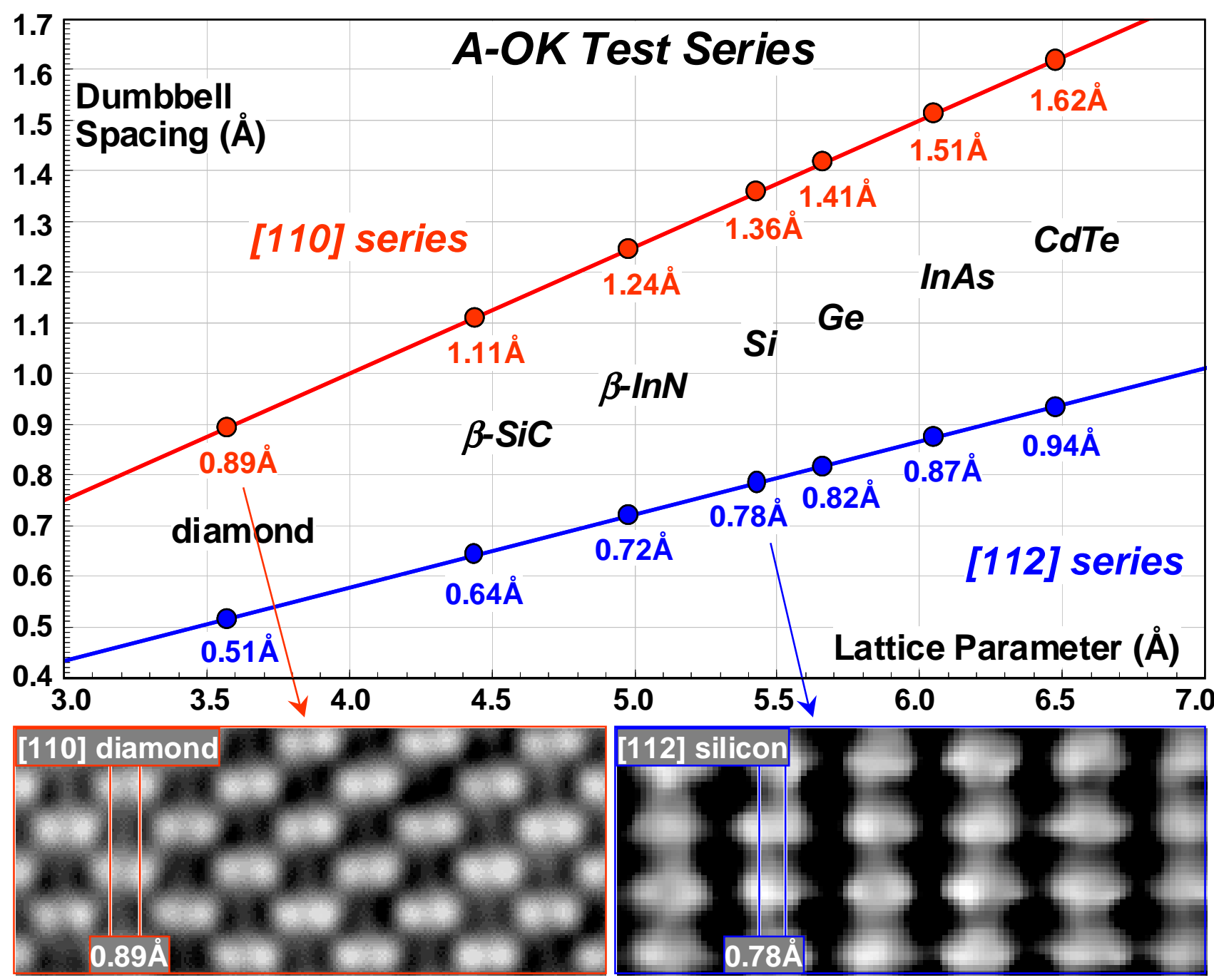

FIG. 1. Graph (top) shows A-OK test specimens with lattice spacings that produce images of atom columns in "dumbbell" pairs with separations from $1.62 \AA$ to $0.51 \AA$ for samples tilted into [110] and [112] orientations. Left O̊̊M image shows $0.89 \AA$ carbon atom spacing in [110] diamond [5]. Right OÅM image shows $0.78 \AA$ silicon atom spacing in [112] silicon. Aberration-corrected by focal-series reconstruction, the images cover the same areas at magnifications of 47 million times.

\section{$\underline{\text { References }}$}

[1] Lord Rayleigh, Philosophical Magazine 47 (1874) 81.

[2] M.A. O'Keefe, 37th Ann. Proc. EMSA, San Antonio, Texas (1979) 556.

[3] D.W. Palmer, www.semiconductors.co.uk, 2003.04 〈http://www.semiconductors.co.uk/>

[4] M.A. O'Keefe, E.C. Nelson, Y.C. Wang \& A. Thust, Philosophical Mag. B 81 (2001) 1861.

[5] M.A. O'Keefe et al. Ultramicroscopy 89, (2001) 215.

[6] W.M.J. Coene, A. Thust, M. Op de Beeck \& D. Van Dyck, Ultramicroscopy 64 (1996) 109.

[7] A. Thust, W.M.J. Coene, M. Op de Beeck \& D. Van Dyck, Ultramicroscopy 64 (1996) 211.

[8] P.E. Batson, N. Dellby \& O. L. Krivanek, Nature 418 (2002) 617.

[9] P.D. Nellist, \& S.J. Pennycook, Microscopy and Microanalysis 6, (2000) 104.

[10] Y. Shao-Horn, L. Croguennec, C. Delmas, E.C. Nelson \& M.A. O'Keefe, Nature Mat. 2 (2003) 464.

[11] M.A. O’Keefe, E.C. Nelson \& L.F. Allard, Microscopy \& Microanalysis 9, (2003) 278.

[12] M.A. O'Keefe, Third TEAM Workshop and Microscopy \& Microanalysis 9, (2003) 936.

[13] Supported by Director, Office of Science, Office of Basic Energy Sciences, Materials Science Division, DOE (contract DE-AC03-76SF00098), and Asst. Sec. for EERE, Office of FreedomCAR and Vehicle Tech., HTML User Program, ORNL, managed by UT-Battelle, LLC for DOE (contract DE-AC05-00OR22725). 